\title{
Distinctive Characteristics of Mobile Advertising in Measuring Consumers' Attitude: An Empirical Study
}

\author{
Mirza A. Haq * Arsalan Mujahid Ghouri ${ }^{\dagger}$
}

\begin{abstract}
Mobile advertising has gained substantial momentum in the past decade as it is expected to surpass more than 100 billion dollars in the near future. However, this domain seems to be insufficient in empirical testing. Hence, the aim of the current research was to empirically examine the determinants of mobile marketing having impact on consumers' attitude. These factors were also mediated by emotional value in order to accomplish consumers' related behavioral outcomes. A quantitative approach based upon a cross-sectional administered survey was employed to collect the data from 343 university going student as respondents. The Partial Least Square (PLS) two step path modeling was used to test the direct and indirect hypotheses. The results indicate that mobile advertising unique features (i.e., timeliness and personalization) directly and indirectly impact consumers' attitude through emotional value. On the contrary, localization element of mobile advertising has been found insignificant in influencing consumers' attitude. Based on the findings of the study, theoretical and practical contributions along with certain limitations and future research recommendations are discussed consequently.
\end{abstract}

Keywords: Mobile advertising, timeliness, localization, personalization, emotional value, attitude, social cognitive theory.

\section{Introduction}

Mobile advertising is one of the most flourishing businesses these days. One such testimony is its novel growth rate in the US only. According to the statistics of 2014, it grew to 19 billion dollars and it is speculated to reach more than 65 billion dollars by the end of 2019, which will account for approximately $75 \%$ of the total digital advertising budget (eMarketer, 2015). Not only the US, but in the global scenario, it is expected to surpass more than 100 billion dollars, which is more than $50 \%$ of what was spent on digital advertising in 2016 (eMarketer, 2015). Penetration of Smart phones and other related mobile devices, particularly in youth, have become the reason of this exceptional growth of mobile advertising.

Few seminal works in mobile marketing domain are important contributions towards the foundation of mobile marketing literature (Grewal, Bart, Spann, \& Zubcsek, 2016; Hofacker, De Ruyter, Lurie, Manchanda, \& Donaldson, 2016). However, it is important to note that these models and frameworks are purely conceptual or exploratory in nature (Varnali \& Toker, 2010) and require empirical testing (Lamberton \& Stephen, 2016)

\footnotetext{
* Iqra University, Karachi. This paper is a part of PhD work.

${ }^{\dagger}$ Montpellier Business School, France \& Universiti Pendidikan Sultan Idris, Malaysia.
} 
to deeply understand their effectiveness and application in mobile marketing domain. Therefore, one of the major reasons to look forward in this field is the absence of empirical researches to test the proposed theories specifically in the context of mobile marketing.

The scope of research in the context of consumers' attitude through mobile marketing is quite high as very few studies have been carried out to examine how and to what extent they are influenced by mobile marketing activities (Hsu \& Lin, 2015; S. J. Kim, Wang, \& Malthouse, 2015) particularly in developing countries (Aslam, Batool, Haq, et al., 2016). Additionally, contradictory claims were often made in studies about significance and intensity of mobile marketing factors to influence their attitude (Dix, Jamieson, \& Shimul, 2016; Hsu \& Lin, 2015; Sam, 2017).

In line with the above discussion, these studies, however, have majorly focused on exploring the factors that makes mobile advertising (MAds) successful as a whole without emphasizing on its individual and unique components - such as timeliness, personalization and localization. Thus, there is a substantial need to examine how unique features of mobile marketing (i.e., timeliness, personalization and localization) influence consumers' attitude.

Another interesting argument which has led to carry out this study was that mobile marketing features did not only affect consumer attitude directly (Venkatesh \& Bala, 2008). It has been highlighted by different scholars that there is a missing link between mobile advertising related factor and consumer related outcomes (Peng, Zhao, \& Zhu, 2016; Venkatesh \& Bala, 2008; Shin, 2015). Prominent researches (Lamberton \& Stephen, 2016; Varnali \& Toker, 2010) indicated that there is a need to study the mediated effect of mobile advertising related factor on consumer attitude through emotional value. Hence, it is important to test the impact of the consumer emotional value by which that mobile advertising related factors affect consumer attitude.

As it has been mentioned earlier that mobile users make up a critical segment for marketers, therefore, their phases of purchase behavior are very important to understand in terms of their usage of smartphones and response towards mobile marketing activities. Keeping in view these issues few questions arise:

RQ1: What is the role of mobile advertising unique characteristics (localization, personalization and timeliness) in forming consumer attitude?

RQ2: How does emotional value mediates the relationship between mobile advertising unique characteristics and consumer attitude?

\section{Literature Review}

\section{Timeliness and Consumer Attitude123}

In mobile marketing perspective, timeliness of ads is considered as one of the unique features that organizations may attain through mobile advertising. Timeliness is defined as the value that consumers derive from delivering services on right time, specifically time-sensitive services, i.e., last-minute arrangements and limited-time travel offers 
(Hourahine \& Howard, 2004; Feng, Fu, \& Qin, 2016). Another stream of scholars (such as Childers, Carr, Peck, and Carson (2002); Rohm, Kaltcheva, and Milne (2013) describe timeliness as the utilitarian value that consumers derive from timely and efficient service delivery. Mobile devices enable consumers to carry these anywhere and anytime; which enable marketers and practitioners to engage consumers 24 hours a day and seven days a week through customized offerings and messages to influence their attitude (Kenny \& Marshall, 2000; Rau, Zhou, Chen, \& Lu, 2014). Merchandisers may send time-critical offerings to target consumers to produce timely responses from them. Consequentially, it provides as opportunity to consumers to make their purchases in convenient, efficient and economical manner. Past studies in the domain of internet advertising (Ho, Bodoff, \& Tam, 2011) and mobile advertising (Feng et al., 2016; Cheung \& To, 2017) depict that timing is one of the most important components of advertising outcome. It is further proposed by Merisavo et al. (2007); Rau et al. (2014) that timely information intensifies acceptance of consumer towards mobile advertising. Thus, persuading mobile users in a timely manner should effectually enhance mobile advertising efficiency. Hence it is proposed that:

Hypothesis 1: Timeliness in mobile marketing activities has a significant impact on consumers' attitude.

\section{Localization and Consumer Attitude}

Localization is one of the unique and significant feature of mobile advertising as compared to traditional modes of advertising. According to Lin, Paragas, Goh, and Bautista (2016); Kaasinen (2003), localization is the extent to which a promotional messages are pertinent and related to specific places. Locations and physical spaces forms consumers' responses to promotional offerings (Dholakia \& Dholakia, 2004). Wireless technology in mobile phones permit service providers to track the location of user through GPS. Thus it provides an opportunity for marketers and practitioners to identify the location of the customer and send messages according to their present location (Lin et al., 2016; Wu, Kao, $\mathrm{Wu}, \&$ Huang, 2015). The element of uniqueness can be maximized through the use of location based information in advertised message (Leppaniemi \& Karjaluoto, 2008; Wu et al., 2015) and issue of irrelevance can be minimized (Feng et al., 2016). For instance, a shopper closer to a retail store may get a message propounding a limited time offer from that retailer. So, localization may enhance the relevance in the advertising message and decrease the level of irritation. As a result, it ends up in acceptance and generation of positive outcomes for the advertised product. Thus, it has been put forward that:

Hypothesis 2: Localization in mobile marketing activities has a significant impact on consumers' attitude. 


\section{Personalization and Consumer Attitude}

Personalization is another unique and important features of mobile advertising. According to scholars (Y. J. Kim \& Han, 2014; Leppaniemi \& Karjaluoto, 2008), personalization means the extent to which an advertised message is according to the needs, preferences, personality, lifestyle, geographical and demographical characteristics of the consumers. The element of personalization performs a very important role is shaping consumers positive perception towards mobile advertising (Feng et al., 2016; Oztas, 2015) in that a mobile device is not generally used by anyone other than its owner. Therefore, consumers look forward to highly customized offerings on their cell phones (Kalinic \& Marinkovic, 2016; Bauer, Reichardt, Barnes, \& Neumann, 2005). Marketers and practitioners may utilize customers' history and feedback as tools to gather information about their preferred choices and tailor their offerings accordingly (Morosan, Morosan, DeFranco, \& DeFranco, 2016). This may provide an opportunity for marketers to treat their key customers in an exclusive and individualized manner and build enduring relationships with them. Additionally, prior researches (Kalinic \& Marinkovic, 2016; Carroll, Barnes, \& Scornavacca, 2005) also supported that consumers are more receptive and positive to those advertising messages which are according to their individualized needs. Consequently, it is anticipated that:

Hypothesis 3: Personalization in mobile marketing activities has a significant impact on consumers' attitude.

\section{Mobile Marketing Features, Emotional Value and Consumer Attitude}

Emotional value in mobile services is acquired particularly through aesthetic attributes of content and having excitement while consuming the service (Huhn et al., 2017). Furthermore, mobile services frequently facilitate emotional communication, for instance, through mobile chat services or ordering picture messages, logos and ring tones that can also be sent as gifts (Huhn et al., 2017; Pura, Gummerus, et al., 2007). Therefore, emotional value is important especially in mobile entertainment services. As per past studies, emotional value is attained when a product or service provokes feelings or affect (Hsu, Chen, Yang, \& Lin, 2017; Sheth, Newman, \& Gross, 1991). Aesthetic enjoyment and connections with earlier experiences, in addition to pleasure or fun experienced for its own sake, produce emotional value (Jimenez \& San-Martin, 2017; Sheth et al., 1991). Moreover, scholars (such as Oyedele and Simpson (2017); Leung and Wei (2000) have stated pleasure and enjoyment as consumers' drives for using mobile services.

Mobile technology use seems to be an emotional experience even in the mobile advertising context, because customers perceive to receive both intrinsic and extrinsic value from mobile advertising services (Feng et al., 2016; Laukkanen, 2006). This research instigate signals of emotional value also achieved by teasing others, which is considered as a positive emotion from the sender's standpoint, but may also turn out to be annoying for the recipient (Pura et al., 2007). Hirschman (1980) suggests that feelings may be e.g. 
joy, but also mentions negative feelings like jealousy, fear or even rage. Nevertheless, the effect of emotional value is proposed to be mainly positive on attitude. Therefore, we propose the following hypothesis:

Hypothesis 4: Emotional value mediates the relation between mobile marketing features (localization [H4a], timeliness [H4b] and personalization [H4c]) and consumers' attitude.

\section{Theoretical Framework}

Figure 1

Theoretical Framework

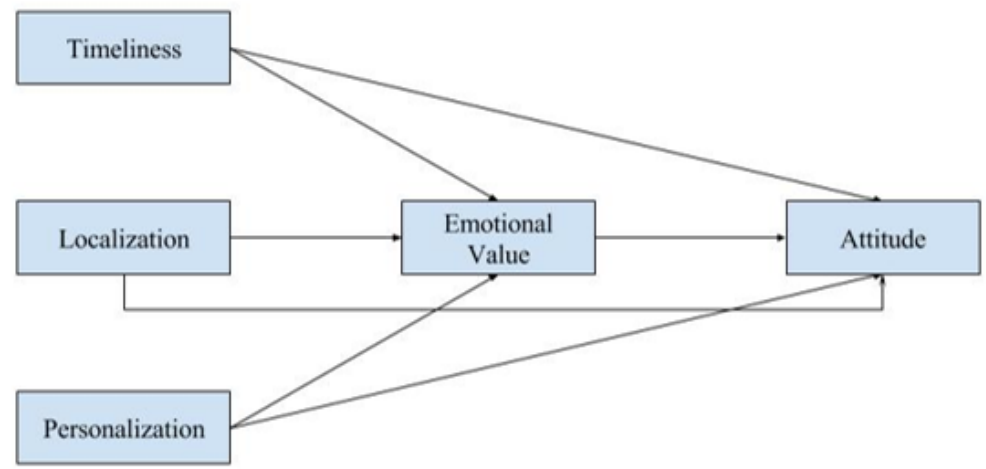

On the basis of reviewed literature, Figure 1 depicts the research framework that shows mobile advertising features (timeliness, localization and personalization) and consumers' attitude. In addition, current research also extends previous literature by examining emotional value as mediating variable between MAd (mobile advertising) features and attitude on the basis of social cognitive theory (Bandura, 2001).

Social cognitive theory is a frame that includes environmental components having an effect on consumer behavior. Social cognitive theory is a learning paradigm as it emphasis on how human beings alter their behavior based on different environmental factors (Pincus, 2004). Behavior is a complicated process that is contingent on present and future goals. The behavior of persons is an outcome of environmental shifts and this can help out anticipate adoption of technological innovations (Ratten \& Ratten, 2007). The main emphasis of social cognitive theory in the innovation domain is on how ones' skills and ability shapes part of behavioral changes that influence adoption levels (Compeau, Higgins, \& Huff, 1999). As far behavior is grounded on learning via social components, social cognitive theory has grown to be more accepted in studies on technology innovation (Compeau et al., 1999).

According to social cognitive theory, human functions in terms of triadic reciprocal causations namely internal personal factors, environmental factors and behavioral factors. Moreover, the socio-structural factors operate through psychological mechanisms 
to produce behavioral effects (Bandura, 2001). Consumer research has represented SCT research in recent times in predicting new technology adoption (Compeau et al., 1999; Keith, Babb, Lowry, Furner, \& Abdullat, 2015; Venkatesh \& Bala, 2008). In general, SCT has been discussed in the perspective of information technology acceptance (Compeau et al., 1999), and in particular, mobile advertising context (Keith et al., 2015). Based on this, it is proposed that this model consists of unique mobile advertising characteristics as the cues exert upon the consumer from external environment and emotional values as a mediator (psychological mechanisms) to produce behavioral effects.

\section{Research Method}

A quantitative approach was adopted through which the data was collected in numerical and factual form for the variables of study and statistical measures were applied on the data to assess findings. The target audience of this study were university-going consumers who are availing the service of any of the five major telecommunication service providers namely Ufone, Telenor, Zong, Warid and Mobilink in Pakistan.

The university going consumers who were enrolled in private universities have been considered as the total population in the current study. As revealed (University wise enrollment of year 2014-15), about 64064 the university aged students who were enrolled in 21 private universities have been considered as the total population in the current study. Therefore, the population of the study is considered to be 64064 which were full-time University students.

The decision about the selection of most suitable sampling method and the sample size depends on many factors. In line with the suggestion of Bryman and Bell (2015); Neuman (2006), decision about selection of sampling method depends upon time, cost and required accuracy. As far as this study is concerned, the list of Private universities is taken as a sampling frame for this study. These Private universities are located in different geographical locations in Pakistan. In line with this view, Saunders (2015) suggest that, under such condition, when the population of the study is distributed in different geographical locations, then the cluster probability sampling is the best option to get a representative sample. The main reason behind this is; it is cost effective and less time consuming in comparison to simple random sampling. In cluster sampling, several clusters are developed by diving the total units in a frame in such a way, that each cluster should be representative of the study population. The cluster could be countries, cities, election districts etc.

For the present study, a multi-stages cluster sampling method was used to collect the required number of data for analysis. All cluster selected for this study with equal probability or with probability proportional sampling. Table 1 describes the details of target population and procedure of sample selection.

In order to collect accurate and reliable data, four enumerators were hired and trained regarding questionnaire administration and field procedure to administer the questionnaire to key informant. These enumerators were provided with detailed review of questionnaire items in order to put the respondent through any instant of ambiguity and mis- 
understanding of the questionnaire items.

\begin{tabular}{lcc} 
Table 1 & & \\
Details of Multi-stage Cluster Sampling & Sub Total & Total \\
\hline Indicator & 33 & 179 \\
\hline Total no. of Universities in Pakistan (Public + Private) & & \\
Federal & 51 & \\
Punjab & 50 & \\
Sindh & 30 & \\
KPK & 08 & \\
Baluchistan & 07 & 75 \\
Azad Jammu \& Kashmir & & \\
Total no. of Private Universities in Pakistan & 08 & \\
Federal & 24 & \\
Punjab & 30 & \\
Sindh & 10 & \\
KPK & 01 & \\
Baluchistan & 02 & \\
Azad Jammu \& Kashmir & & 30 \\
No. of Private Universities in Sindh & 29 & \\
Karachi & 01 & \\
Hyderabad & & 29 \\
No. of Private Universities in Karachi & & \\
\hline Source: HEC website (http://hec.gov.pk/) &
\end{tabular}

The survey instrument of the study used a Likert-type interval scale, namely Strongly Agree, Agree, Neutral, Disagree, and Strongly Disagree to collect the participant's responses to the survey questions. A numerical scale from 1 to 5 identifies the intervals of scale, with 5 indicating the strongest settlement with the provided survey answer.

This questionnaire for this research study was divided into four sections. First section depicts the demographic data of the consumers. The next section describes the mobile advertising related factors adapted from (Feng et al., 2016; Merisavo et al., 2007; Pihlstrom et al., 2008). Next section discusses the behavioral outcomes of advertising via mobiles devices adapted from (Lee \& Jun, 2007; Soutar \& Sweeney, 2003; Xu, 2006). Last section asks the respondents to answer open ended questions related to mobile advertising.

To analyze the data produced by the survey, a set of statistical procedures such as measurement model and SEM with mediation analysis were applied in two step approach using SmartPLS 3.

\section{Evaluation of Measurement Model}

Measurement with reflective indicators is analyzed by the validity and the reliability of their respective constructs. In order to measure the reliability of the constructs outer loadings of their respective indicators were analyzed. See Table 3.

According to this table, most of the indicators have load down on their respective construct larger than of 0.70 . The common criteria of the loadings suggest that every indicator has to be load above 0.7 a thumb rule (Yoo \& Alavi, 2001) but some author recommended that Indicators with weaker outer loadings (i.e 0.5 to 0.7 ) can be retain on the basis of their contribution in Average Variance Extracted (Wong, 2013). Weaker outer loadings of the item (below the 0.4) always discarded from the model (Hair, Hult, Ringle, 
\& Sarstedt, 2014). The loadings presented in Table 3 confirm the reliability and validity of the indicator as all the values lying between 0.5 and 0.7 .

Table 2

Details of Private Universities in Karachi

\begin{tabular}{lccc}
\hline Private Universities in Karachi & $\begin{array}{c}\text { Total Enrollment } \\
\mathbf{2 0 1 4 - 2 0 1 5}\end{array}$ & $\begin{array}{c}\text { Proportion in } \\
\text { \%age }\end{array}$ & $\begin{array}{c}\text { Administered } \\
\text { Questionnaires }\end{array}$ \\
\hline Aga Khan University & 1693 & $2.64 \%$ & 11 \\
Greenwich University, Karachi & 1134 & $1.77 \%$ & 07 \\
Habib University, Karachi & 108 & $0.17 \%$ & 01 \\
Indus University, Karachi & 2839 & $4.43 \%$ & 18 \\
Institute of Business Management, Karachi & 3965 & $6.19 \%$ & 25 \\
Institute of Business \& Technology, Karachi & 2161 & $3.37 \%$ & 13 \\
Institute of Business Administration, Karachi & 3492 & $5.45 \%$ & 22 \\
Iqra University, Karachi & 5801 & $9.06 \%$ & 36 \\
Karachi Institute of Economics \& Technology & 3887 & $6.07 \%$ & 24 \\
Karachi School of Business \& Leadership & 106 & $0.17 \%$ & 02 \\
Preston University, Karachi & 4277 & $6.68 \%$ & 27 \\
Jinnah University for Women & 5382 & $8.40 \%$ & 34 \\
Dadabhoy Institute of Higher Education & 5524 & $8.62 \%$ & 34 \\
DHA Suffa University & 1035 & $1.62 \%$ & 06 \\
Baqai Medical University & 1722 & $2.69 \%$ & 11 \\
Hamdard University & 6921 & $10.80 \%$ & 43 \\
Nazeer Hussain University & 118 & $0.18 \%$ & 01 \\
Shaheed Zulfiqar Ali Bhutto Institute of Science and Technology & 5984 & $9.34 \%$ & 37 \\
Sir Syed University of Engineering and Technology & 6030 & $9.41 \%$ & 38 \\
Textile Institute of Pakistan & 275 & $0.43 \%$ & 02 \\
Ziauddin University & 1610 & $2.51 \%$ & 10 \\
Total & 64064 & $100.00 \%$ & 401 \\
\hline
\end{tabular}

Table 3

Evaluation of Model

\begin{tabular}{clccccc}
\hline Construct & Item & Loading & CA & CR & AVE & Outer Weight \\
\hline \multirow{5}{*}{ Attitude } & Attitude_1 & 0.876 & & & & 0.262 \\
& Attitude_2 & 0.877 & 0.898 & 0.929 & 0.766 & 0.278 \\
& Attitude_3 & 0.886 & & & & 0.307 \\
& Attitude_4 & 0.862 & & & & 0.298 \\
& Emotional Value_1 & 0.882 & & & & 0.301 \\
Emotional Value & Emotional Value_2 & 0.903 & 0.861 & 0.907 & 0.711 & 0.307 \\
& Emotional Value_3 & 0.855 & & & & 0.296 \\
& Emotional Value_4 & 0.720 & & & & 0.259 \\
Localization & Localization_1 & 0.88 & & & & 0.463 \\
& Localization_2 & 0.823 & 0.764 & 0.863 & 0.679 & 0.395 \\
& Localization_3 & 0.740 & & & & 0.351 \\
& Timeliness_1 & 0.852 & & & & 0.280 \\
& Timeliness_2 & 0.707 & & & & 0.266 \\
& Timeliness_3 & 0.855 & & & & 0.304 \\
& Timeliness_4 & 0.850 & & & & 0.310 \\
& Peronalization_1 & 0.792 & & & \multirow{2}{*}{0.373} \\
Personalization & Peronalization_2 & 0.970 & 0.752 & 0.858 & 0.669 & 0.440 \\
& Peronalization_3 & 0.861 & & & & 0.407 \\
\hline
\end{tabular}

After outer loadings, convergent validity shows the cronbach's alpha, composite reliability and Average variance extracted. Variable's composite reliabilities in the table are greater than the value of 0.7 (Numally, 1978; Peterson \& Kim, 2013). For the convergent validity, composite reliability (CR) of all the construct were above the threshold value of 0.8 and the value of AVE was greater than 0.5 , which indicates that at least 50 percent 
variance of the indicators could be explained by the variables (Hair et al., 2014; Henseler, Ringle, \& Sinkovics, 2009). As seen in table 4, the AVE value of each variable is greater than 0.5 . Hence convergent validity analyzed and fulfilled.

Table 4

Discriminant Validity

\begin{tabular}{lccccc}
\hline & Attitude & $\begin{array}{c}\text { Emotional } \\
\text { Value }\end{array}$ & Localization & Personalization & Timeliness \\
\hline Attitude & $\mathbf{0 . 8 7 7}$ & & & & \\
Emotional Value & 0.574 & $\mathbf{0 . 8 4 0}$ & & & \\
Localization & 0.362 & 0.264 & $\mathbf{0 . 7 8 6}$ & & \\
Personalization & 0.287 & 0.313 & 0.460 & $\mathbf{0 . 7 9 5}$ & \\
Timeliness & 0.500 & 0.356 & 0.649 & 0.465 & $\mathbf{0 . 7 9 6}$ \\
\hline
\end{tabular}

For the discriminant validity, this research has adopted the method of Fornell and Larcker (1981) in which it is suggested that AVE value of the latent variable higher than the correlation among the construct. Theoretically, for examine the establishment of discriminant validity, the root-square of AVE must be greater than the correlations between the constructs (Hair et al., 2014). This criterion is verified as shown in table 4 . In terms of mobile advertising (MAd) characteristics, timeliness, localization and personalization stimuli were considered to study the direct and indirect effects upon consumer related marketing outcomes. PLS SEM was used to test the model and associated hypotheses. According to the results, all the constructs were found reliable and valid. In the final model three MAd related latent variables namely timeliness, localization and personalization were path analyzed.

\section{Results}

First hypothesis deals with the direct effect of timeliness on consumer attitude. As per the results mentioned in table 5, the direct impact of timeliness have been found significant for emotional value and attitude (e.g., $\mathrm{p}<0.001$ ). Moreover, these significant paths has shown a positive coefficient value; which implies that if mobile advertisements are sent and targeted at the right time, the marketing outcomes will also be positive.

Second hypothesis deals with the direct effect of personalization on consumer attitude. As per the results mentioned in table 5, the direct impact of personalization have been found significant for emotional value (e.g., $\mathrm{p}<0.01$ ) and insignificant for consumer attitude where the associated $t$ value is not beyond the range of 1.96 for the mentioned construct. Moreover, personalization has shown a positive coefficient value; which implies that if mobile advertisements are personalized according to the needs of the consumers, emotional value in the consumers will also be positive.

Third (H3) and fourth (H4a) hypotheses deals with the direct and indirect effect of localize context of mobile ads on consumers' behavioral outcomes. According to the results, the impact of localization have been found insignificant for the behavioral outcomes (e.g., $\mathrm{p}>0.05)$. This implies that localized context of mobile ads do not directly or indirectly entice consumers to have a positive behavior towards ads. 


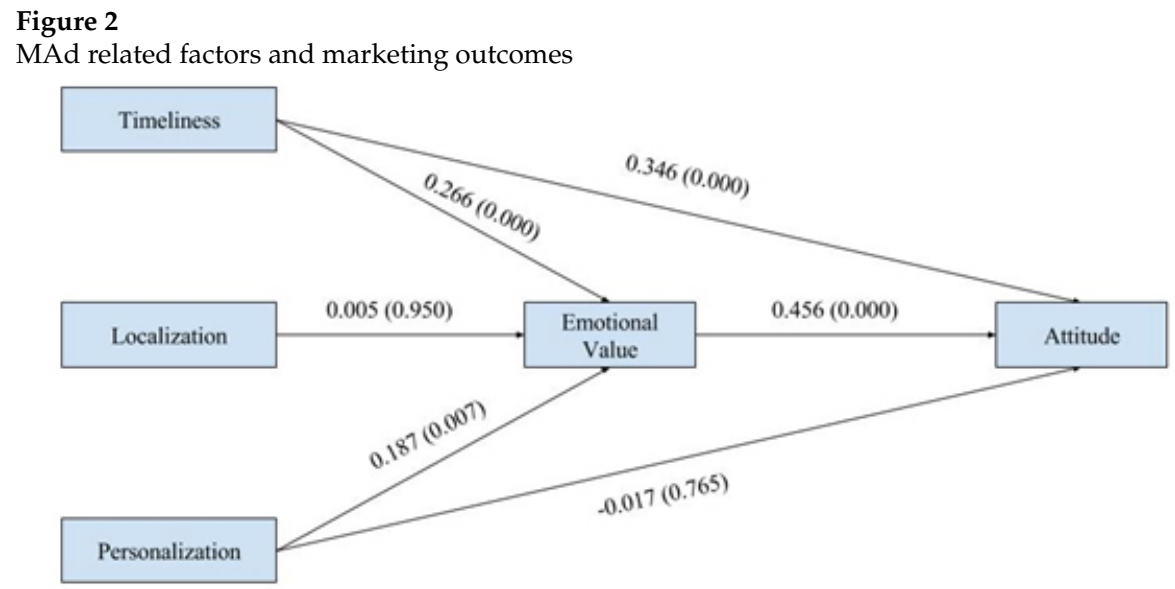

Fifth, and sixth hypotheses deals with the mediated effects of timeliness and personalization on consumer behavioral outcomes. As per the results mentioned in table 5, the indirect impact of timeliness and personalization have been found significant and positive for behavioral outcomes (e.g., $p<0.05$ and the associated $t$ value is greater than 1.96) in general and attitude in particular. Moreover, it has been previously found that the direct paths from personalization to attitude is insignificant $(\mathrm{p}>0.05)$; therefore, it portrays a case of full mediation as suggested by Hayes, (2013). On the other hand, the direct paths from timeliness to attitude is significant $(\mathrm{p}>0.05)$; therefore, there is partial mediation (Hayes, 2013). This implies that emotional value fully mediates the relation between personalization and consumers' attitude and partially mediated in case of timeliness and attitude.

Table 5

Mobile Advertising Related Factors and Marketing Outcomes

\begin{tabular}{lccccccccc}
\hline & \multicolumn{3}{c}{ Direct Effects } & \multicolumn{3}{c}{ Indirect Effects } & \multicolumn{3}{c}{ Total Effects } \\
& Beta & SE & Sig. & Beta & SE & Sig. & Beta & SE & Sig. \\
\hline Emotional_Value ->Attitude & 0.456 & 0.050 & 0.000 & & & & 0.460 & 0.050 & 0.000 \\
Localization ->Attitude & & & & 0.006 & 0.030 & 0.950 & 0.006 & 0.030 & 0.950 \\
Localization -> Emotional_Value & 0.005 & 0.070 & 0.950 & & & & 0.005 & 0.070 & 0.950 \\
Personalization ->Attitude & -0.017 & 0.060 & 0.765 & 0.090 & 0.030 & 0.010 & 0.070 & 0.070 & 0.300 \\
Personalization -> Emotional_Value & 0.187 & 0.070 & 0.007 & & & & 0.190 & 0.070 & 0.010 \\
Timeliness -> Attitude & 0.346 & 0.060 & 0.000 & 0.120 & 0.030 & 0.000 & 0.470 & 0.060 & 0.000 \\
Timeliness ->Emotional_Value & 0.266 & 0.070 & 0.000 & & & & 0.270 & 0.070 & 0.000 \\
\hline
\end{tabular}

In line with the above discussions, it is concluded with at least $95 \%$ confidence level that features (Timeliness, Personalization) of mobile marketing activities have a significant direct and/or indirect impact on consumer attitude through emotional value. On the other hand, localization do no prone to affect these behavioral outcomes directly or indirectly. 


\section{Discussion}

\section{Timeliness and Consumer Attitude}

As far as timeliness is concerned, it is also found to significantly affecting consumers' attitude. In other words, the indirect path from timeliness to mobile viral marketing through emotional value as a focal mediator has been found statistically significant. This infers that if ad (message) is received right at the time it is best needed, it is more likely to bring out a wow factor out of consumer and one will accept the information received through mobile advertising. Similarly, this will, afterwards, transform into a positive attitude. Consequently it will culminate in actual purchase. These results are associated with studies in the context of mobile advertising (Feng et al., 2016) and internet advertising (Merisavo et al., 2007) which states that time-sensitive messages are main ingredients of advertising acceptance.

\section{Localization and Consumer Attitude}

On the contrary, the direct and indirect paths from localization to behavioral outcomes were insignificant and do not affect consumers' attitude. Past researches Feng et al. (2016) stated that localization has a significant impact in forming consumer attitude. However, current research findings are in contrast to these findings. One of the possible reasons might be that past researches were conducted in the context of developed countries (Feng et al., 2016); however, in developing countries like Pakistan, the concept of localization of MAds is relatively new. Therefore, consumers rarely receive localized MAds on their cell phones. Because of this rare exposure, consumer attitude is not reflected through localization.

\section{Personalization and Consumer Attitude}

In line with the above discussion, result indicates that personalization as mobile advertising characteristic has significant impact on consumers' attitude. It means that if the marketer or organization advertise its products that are relevant and according to the requirements of the consumers, then it may transform into positive attitude. In consequential manner, if marketing via cell phone is customized according to receiver's needs, one is more likely to arise positive feelings and emotion towards that. As a result, it may forms a positive attitude about the advertised product. These findings are consistent with past empirical researches (Feng et al., 2016; Yuan \& Tsao, 2003) which posited that level of personalization play an important role in forming consumers' perceptions of mobile advertising. These results also correlated with studies which reveals that consumers are more receptive to mobile advertising if it is portrayed according to their taste and preference (Carroll et al., 2005; Muk, 2007).

In conclusion, results reveal a significant and positive direct and indirect relationship between two unique mobile advertising features (i.e., timeliness and personalization) and 
consumer attitude through emotional value as a focal mediator. This, in order words, indicates that those who receive timely and customized messages via mobile phone are more likely to respond positively through the communication they receive from mobile marketing activities. These findings are consistent with Social Cognitive theory (Bandura, 2001) for direct and indirect relationships between external factors and behavioral outcomes. However, there is no direct or indirect role of localization in influencing consumer attitude.

\section{Theoretical Contribution}

The current research enhances the consumer behavior literature in the context of mobile marketing. The study proposes and empirically tests a framework encompassing two unique mobile advertising features to influence consumers' attitude. Moreover, the results of the study also provides empirical support for Grewal et al. (2016); Shankar, Carpenter, and Hamilton (2012).

Secondly, the current research has made an effort to contribute in the body of literature by operationalizing unique mobile advertising features to suit into mobile marketing context. Drawing upon the social cognitive theory, the dimensions of mobile advertising (MAd) related factors were sensibly selected and modified to fit into the context of current research. MAd characteristics (such as timeliness, personalization and localization), were incorporated due to their novelty and relevancy in mobile marketing context. In the proposed framework these three dimensions were observed to be crucial components of attitude in of mobile marketing context. Thus, in relation to the social cognitive theory, it is suggested to incorporate unique MAd characteristics as important themes under cognitive component as indicator of behavioral outcomes (i.e., attitude) in mobile marketing context.

Thirdly, the current research enhances the literature by studying the indirect influence of emotional value to affect the relationship between mobile marketing stimuli (timely and personalized features) and attitude in mobile marketing context. Drawing upon social cognitive theory, the current study sheds light on how emotional value can be a reason of relationship between cognitive components (i.e., mobile marketing features) and behavioral outcome (i.e., attitude). The results reveal that emotional value does mediate the relationship between two exclusive features of mobile marketing and attitude. Thus, the current research contributes to the consumer behavior literature by recommending that emotional value can be a reason of relationship (mediator) between mobile marketing elements and attitude. The contribution of this research depends on the fact that derived emotional value is an important factor in predicting attitude in mobile marketing context.

On the whole, the current research contributes to the literature by integrating and empirically testing the proposed model and providing a direction for future researches on examining and giving more explanations on localization as a consequential factor to affect consumer attitude in mobile marketing context. 


\section{Practical Contribution}

The results of this research offer numerous managerial insinuations for business practitioners and marketers engaged in the mobile marketing context. More precisely, the recognition of important components permits business practitioners and marketers to form suitable marketing strategies and enrich their long term business goals. The current research explains the critical problems that demand attention in order to systematically comprehend attitude in mobile marketing context. Hence, the inferences drawn from the research findings will be useful for practitioners because they will now have a better understanding of the components that can influence the consumers' attitude.

As MAd characteristics have a significant positive impact on attitude in the context of mobile marketing, business practitioners and marketers should emphasize these factors (timeliness and personalization) and give special attention to ensure their marketing strategies, specifically mobile marketing strategies are structured to influence consumers' attitude.

Moreover, marketing practices in Asian markets are primarily contingent upon western influence; however, there lies considerable behavioral differences across consumers of developed and developing economies. The results of current research extends the literature of consumer behavior by delineating key factors that influence attitude towards purchase in the context of mobile marketing within developing economies, particularly in South Asian countries. At the same time, there has been a substantial growth in the wireless advertising segment within this territory, which indicates rising trend for advertising via mobile phones. Hence, these findings can help current and potential business practitioners and marketers in South Asia by expanding their knowledge of consumer behavior in the context of mobile marketing, and highlighting the underlying connection between cognitive and behavioral components from consumer perspective.

\section{Limitations and Future Research}

This research has provided some fascinating theoretical input yet it surrounds with certain unavoidable limitations that should be emphasized. First, the emphasis of current research was on the marketing activities through mobile phones only. Therefore, the outcomes of this research should be applied cautiously to other media such as print media, broadcast media etc.

Second, this research was carried out in Pakistan, and replicating the research model to other developing economies where mobile marketing has acquired popularity needs further exploration. Indeed, developing economies have diverse cultures that bring about dissimilar consumer behaviors. Thus, depending upon the scope of research, cultural factors can be studied and incorporated within the current model as a moderator to vary across borders.

Third, the research was not specified to any particular products and the scope of research was intentionally kept general. Therefore, these results may vary if studied according to specific product or industry. For example, results for high involvement products may differ from low involvement products. Fourth, the study was limited to the only 
one time data collection that is cross-sectional study and the behavior of the consumers may change if studied over the period of time for better understanding and validating the findings of current research. It can be helpful by taking the data few more times from the same respondents to check whether their behavior is same or it is constantly changing over the period of time for the better decision making. Fifth, no moderator was gauged by the researcher that influences the actual purchasing of the consumers which may be necessary in future.

Finally, emotional value was based on factors from the theory of consumption values model (Huang, Chou, \& Lin, 2010), but only one factor was employed and consider most appropriate in this study (emotional value). Other dimensions were not used and dropped to avoid complexity in the proposed model. Future studies might consider additional values, such as financial value and epistemic value, as dimensions of perceived value in a different context. 


\section{References}

Aslam, W., Batool, M., Haq, Z. U., et al. (2016). Attitudes and behaviour of the mobile phones users towards SMS advertising: A study in an emerging economy. Journal of Management Sciences, 3(1), 63-80.

Bandura, A. (2001). Social cognitive theory of mass communication. Media Psychology, 3(3), 265-299.

Bauer, H. H., Reichardt, T., Barnes, S. J., \& Neumann, M. M. (2005). Driving consumer acceptance of mobile marketing: A theoretical framework and empirical study. Journal of Electronic Commerce Research, 6(3), 188-192.

Bryman, A., \& Bell, E. (2015). Business research methods. Oxford University Press, USA.

Carroll, A., Barnes, S. J., \& Scornavacca, E. (2005). Consumers perceptions and attitudes towards SMS Mobile Marketing in New Zealand. International Conference on Mobile Business (ICMB'05), 434-440. doi: 10.1109/ICMB.2005.30

Cheung, M. F., \& To, W. (2017). The influence of the propensity to trust on mobile users' attitudes toward in-app advertisements: An extension of the theory of planned behavior. Computers in Human Behavior, 76, 102-111.

Childers, T. L., Carr, C. L., Peck, J., \& Carson, S. (2002). Hedonic and utilitarian motivations for online retail shopping behavior. Journal of Retailing, 77(4), 511-535.

Compeau, D., Higgins, C. A., \& Huff, S. (1999). Social cognitive theory and individual reactions to computing technology: A longitudinal study. MIS Quarterly, 23(2), 145158.

Dholakia, R. R., \& Dholakia, N. (2004). Mobility and markets: Emerging outlines of m-commerce. Journal of Business Research, 57(12), 1391-1396.

Dix, S., Jamieson, K., \& Shimul, A. S. (2016). SMS advertising the Hallyu way: Drivers, acceptance and intention to receive. Asia Pacific Journal of Marketing and Logistics, 28(2), 366-380.

eMarketer. (2015). Mobile will account for $72 \%$ of US Digital ad spend by 2019. Retrieved from https://www.emarketer.com/Article/Mobile-Will -Account-72-of-US-Digital-Ad-Spend-by-2019/1012258

Feng, X., Fu, S., \& Qin, J. (2016). Determinants of consumers' attitudes toward mobile advertising: The mediating roles of intrinsic and extrinsic motivations. Computers in Human Behavior, 63, 334-341. doi: 10.1016/j.chb.2016.05.024

Fornell, C., \& Larcker, D. F. (1981). Structural equation models with unobservable variables and measurement error: Algebra and statistics. Journal of Marketing Research, 18(3), 382-388.

Grewal, D., Bart, Y., Spann, M., \& Zubcsek, P. P. (2016). Mobile advertising: A framework and research agenda. Journal of Interactive Marketing, 34, 3-14. doi: 10.1016/j.intmar .2016.03.003

Hair, J. F. J., Hult, G. T. M., Ringle, C., \& Sarstedt, M. (2014). A primer on partial least squares structural equation modeling (PLS-SEM). Long range planning. Sage Publications.

Henseler, J., Ringle, C. M., \& Sinkovics, R. R. (2009). The use of partial least squares path modeling in international marketing. In New challenges to international marketing (pp. 277-319). Emerald Group Publishing Limited. 
Hirschman, E. C. (1980). Innovativeness, novelty seeking, and consumer creativity. Journal of Consumer Research, 7(3), 283-295.

Ho, S. Y., Bodoff, D., \& Tam, K. Y. (2011). Timing of adaptive web personalization and its effects on online consumer behavior. Information Systems Research, 22(3), 660-679.

Hofacker, C. F., De Ruyter, K., Lurie, N. H., Manchanda, P., \& Donaldson, J. (2016). Gamification and mobile marketing effectiveness. Journal of Interactive Marketing, 34, 25-36. doi: 10.1016/j.intmar.2016.03.001

Hourahine, B., \& Howard, M. (2004). Money on the move: Opportunities for financial service providers in the 'third space'. Journal of Financial Services Marketing, 9(1), 57-67.

Hsu, C.-L., Chen, Y.-C., Yang, T.-N., \& Lin, W.-K. (2017). Do website features matter in an online gamification context? Focusing on the mediating roles of user experience and attitude. Telematics and Informatics, 34(4), 196-205.

Hsu, C.-L., \& Lin, J. C.-C. (2015). What drives purchase intention for paid mobile apps?An expectation confirmation model with perceived value. Electronic Commerce Research and Applications, 14(1), 46-57.

Huang, C.-Y., Chou, C.-J., \& Lin, P.-C. (2010). Involvement theory in constructing bloggers' intention to purchase travel products. Tourism Management, 31(4), 513-526.

Huhn, A. E., Khan, V.-J., Ketelaar, P., van't Riet, J., Konig, R., Rozendaal, E., .. Markopoulos, P. (2017). Does location congruence matter? A field study on the effects of location-based advertising on perceived AD intrusiveness, relevance \& value. Computers in Human Behavior, 73, 659-668. doi: 10.1016/j.chb.2017.03.003

Jimenez, N., \& San-Martin, S. (2017). Attitude toward m-advertising and m-repurchase. European Research on Management and Business Economics, 23(2), 96-102.

Kaasinen, E. (2003). User needs for location-aware mobile services. Personal and Ubiquitous Computing, 7(1), 70-79.

Kalinic, Z., \& Marinkovic, V. (2016). Determinants of users' intention to adopt mcommerce: An empirical analysis. Information Systems and e-Business Management, 14(2), 367-387.

Keith, M. J., Babb, J. S., Lowry, P. B., Furner, C. P., \& Abdullat, A. (2015). The role of mobile-computing self-efficacy in consumer information disclosure. Information Systems Journal, 25(6), 637-667.

Kenny, D., \& Marshall, J. F. (2000). Contextual marketing. Harvard Business Review, 78(6), 119-25.

Kim, S. J., Wang, R. J.-H., \& Malthouse, E. C. (2015). The effects of adopting and using a brand's mobile application on customers' subsequent purchase behavior. Journal of Interactive Marketing, 31, 28-41. doi: 10.1016/j.intmar.2015.05.004

Kim, Y. J., \& Han, J. (2014). Why smartphone advertising attracts customers: A model of web advertising, flow, and personalization. Computers in Human Behavior, 33, 256-269. doi: 10.1016/j.chb.2014.01.015

Lamberton, C., \& Stephen, A. T. (2016). A thematic exploration of digital, social media, and mobile marketing: Research evolution from 2000 to 2015 and an agenda for future inquiry. Journal of Marketing, 80(6), 146-172. 
Laukkanen, T. (2006). Consumer value drivers in electronic banking. University of Kuopio Kuopio, Finland.

Lee, T., \& Jun, J. (2007). Contextual perceived value? Investigating the role of contextual marketing for customer relationship management in a mobile commerce context. Business Process Management Journal, 13(6), 798-814.

Leppaniemi, M., \& Karjaluoto, H. (2008). Exploring the effects of gender, age, income and employment status on consumer response to mobile advertising campaigns. Journal of Systems and Information Technology, 10(3), 251-265.

Leung, L., \& Wei, R. (2000). More than just talk on the move: Uses and gratifications of the cellular phone. Journalism \& Mass Communication Quarterly, 77(2), 308-320.

Lin, T. T., Paragas, F., Goh, D., \& Bautista, J. R. (2016). Developing location-based mobile advertising in Singapore: A socio-technical perspective. Technological Forecasting and Social Change, 103, 334-349.

Merisavo, M., Kajalo, S., Karjaluoto, H., Virtanen, V., Salmenkivi, S., Raulas, M., \& Leppaniemi, M. (2007). An empirical study of the drivers of consumer acceptance of mobile advertising. Journal of Interactive Advertising, 7(2), 41-50.

Morosan, C., Morosan, C., DeFranco, A., \& DeFranco, A. (2016). Modeling guests' intentions to use mobile apps in hotels: The roles of personalization, privacy, and involvement. International Journal of Contemporary Hospitality Management, 28(9), 1968-1991.

Muk, A. (2007). Consumers' intentions to opt in to SMS advertising: a cross-national study of young Americans and Koreans. International Journal of Advertising, 26(2), 177-198.

Neuman, W. L. (2006). Social research methods: Qualitative and quantitative approaches. US: Pearson Education.

Numally, J. C. (1978). Psychometric theory. NY: McGraw-Hill.

Oyedele, A., \& Simpson, P. M. (2017). Streaming apps: What consumers value (In Press). Journal of Retailing and Consumer Services.

Oztas, Y. B. B. (2015). The increasing importance of mobile marketing in the light of the improvement of mobile phones, confronted problems encountered in practice, solution offers and expectations. Procedia-Social and Behavioral Sciences, 195, 10661073.

Peng, X., Zhao, Y. C., \& Zhu, Q. (2016). Investigating user switching intention for mobile instant messaging application: Taking WeChat as an example. Computers in Human Behavior, 64, 206-216. doi: 10.1016/j.chb.2016.06.054

Peterson, R. A., \& Kim, Y. (2013). On the relationship between coefficient alpha and composite reliability. Journal of Applied Psychology, 98(1), 194-198.

Pihlstrom, M., et al. (2008). Perceived value of mobile service use and its consequences. Publications of the Swedish School of Economics and Business Administration. Retrieved from https://doi.org/citeulike-article-id:2625352

Pincus, J. (2004). The consequences of unmet needs: The evolving role of motivation in consumer research. Journal of Consumer Behaviour, 3(4), 375-387.

Pura, M., Gummerus, J., et al. (2007). Discovering perceived value of mobile services (Tech. Rep.). 
Ratten, V., \& Ratten, H. (2007). Social cognitive theory in technological innovations. European Journal of Innovation Management, 10(1), 90-108.

Rau, P.-L. P., Zhou, J., Chen, D., \& Lu, T.-P. (2014). The influence of repetition and time pressure on effectiveness of mobile advertising messages. Telematics and Informatics, 31(3), 463-476.

Rohm, A. D., Kaltcheva, V., \& Milne, G. (2013). A mixed-method approach to examining brand-consumer interactions driven by social media. Journal of Research in Interactive Marketing, 7(4), 295-311.

Sam, S. (2017). Towards an empowerment framework for evaluating mobile phone use and impact in developing countries. Telematics and Informatics, 34(1), 359-369.

Saunders, M. N. (2015). Research methods for business students. Pearson Education India.

Shankar, V., Carpenter, G. S., \& Hamilton, J. F. B. A. (2012). Handbook of marketing strategy. Edward Elgar Publishing, Incorporated.

Sheth, J. N., Newman, B. I., \& Gross, B. L. (1991). Why we buy what we buy: A theory of consumption values. Journal of Business Research, 22(2), 159-170.

Shin, D.-H. (2015). Effect of the customer experience on satisfaction with smartphones: Assessing smart satisfaction index with partial least squares. Telecommunications Policy, 39(8), 627-641.

Soutar, G. N., \& Sweeney, J. C. (2003). Are there cognitive dissonance segments? Australian Journal of Management, 28(3), 227-249.

Varnali, K., \& Toker, A. (2010). Mobile marketing research: The-state-of-the-art. International Journal of Information Management, 30(2), 144-151.

Venkatesh, V., \& Bala, H. (2008). Technology acceptance model 3 and a research agenda on interventions. Decision Sciences, 39(2), 273-315.

Wong, K. K.-K. (2013). Partial least squares structural equation modeling (PLS-SEM) techniques using SmartPLS. Marketing Bulletin, 24(1), 1-32.

Wu, C., Kao, S.-C., Wu, C.-C., \& Huang, S. (2015). Location-aware service applied to mobile short message advertising: Design, development, and evaluation. Information Processing \& Management, 51(5), 625-642.

$\mathrm{Xu}, \mathrm{D}$. J. (2006). The influence of personalization in affecting consumer attitudes toward mobile advertising in China. Journal of Computer Information Systems, 47(2), 9-19.

Yoo, Y., \& Alavi, M. (2001). Media and group cohesion: Relative influences on social presence, task participation, and group consensus. MIS Quarterly, 25(3), 371-390.

Yuan, S.-T., \& Tsao, Y. W. (2003). A recommendation mechanism for contextualized mobile advertising. Expert Systems with Applications, 24(4), 399-414. 